\title{
A case of miliary tuberculosis with disseminated choroidal haemorrhages
}

Department of

Ophthalmology, Tohoku University School of Medicine, 1-1 Seiryoumachi, Sendai, Miyagi 980 , Japan

T Shiono

S-i Abe

Department of Ophthalmology, Iwaki Kyoritsu General Hospital

THoriuchi

Correspondence to:

T Shiono, MD

Accepted for publication

23 November 1989

Takashi Shiono, Shin-ichi Abe, Toshio Horiuchi

\begin{abstract}
A 20-year-old Japanese man had generalised miliary tuberculosis. Although he had no ocular symptoms, choroidal miliary tuberculosis with pleomorphic findings, including disseminated choroidal haemorrhages, was noted in both fundi. The haemorrhages disappeared as the patient's condition improved on medical therapy. Disseminated choroidal haemorrhages should be looked for in patients with miliary tuberculosis.
\end{abstract}

Uveal involvement has been described in primary, recurrent, and miliary forms of tuberculosis. ${ }^{1-6}$ Although common ocular findings of the disease are uveitis and choroidal tuberculoma, these changes are often pleomorphic, and the roles of bacteriological and immunological variables are unknown. ${ }^{16}$ The diagnosis of tuberculosis implies the need for appropriate systemic therapy. We treated a man with miliary tuberculosis and disseminated choroidal haemorrhages. The haemorrhages disappeared as the patient's general condition improved with chemotherapy.

\section{Case report}

A 20-year-old Japanese man was admitted to the hospital on 28 April 1986 with a two-month history of cough, fever, and chills. He had been diagnosed as having nephrotic syndrome in October 1985 and had been taking a steroid since then.

A chest $x$ ray film taken on admission to hospital revealed pleuritis. Echography of the abdomen showed hepatosplenomegaly. A computed tomographic scan of the brain disclosed multiple disseminated dense lesions. Cultures of the sputum and pleural effusion were positive for Mycobacterium tuberculosis. The diagnosis of generalised miliary tuberculosis was made. The

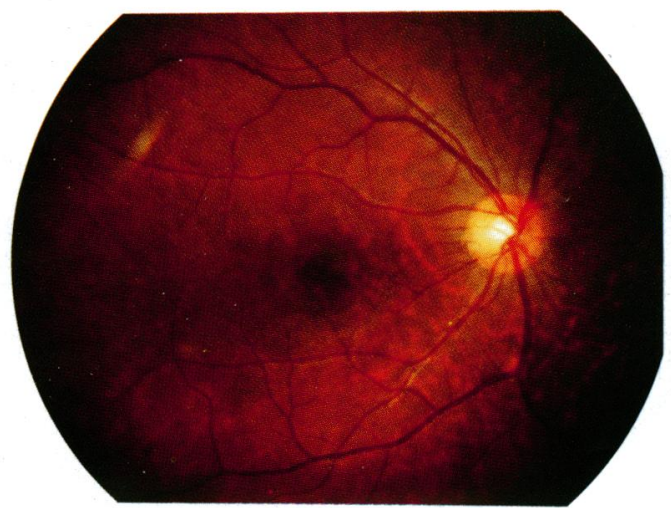

Figure 1: Right eye: small white lesion inferotemporal to the macula.

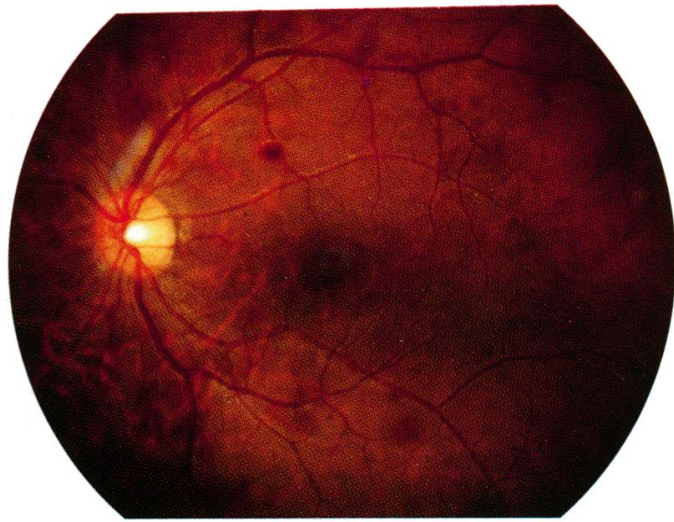

Figure 2: Left eye: disseminated choroidal haemorrhages and one retinal haemorrhage.

following laboratory findings were noted: white blood cell count (WBC), $4 \cdot 4 \times 10^{9} / 1$; red blood cell count $(\mathrm{RBC}), 4 \cdot 1 \times 10^{12} / 1$; haemoglobin $(\mathrm{Hb})$, $10.5 \mathrm{~g} / \mathrm{dl}$; haematocrit, $32.3 \%$; platelet count, $411 \times 10^{9} / 1$; bleeding time, $5 \mathrm{~min} 30 \mathrm{~s}$; coagulation time, $8 \mathrm{~min}$.

The patient was treated with isoniazid (750 mg/day), rifampicin (450 mg/day), and ethanbutol ( $750 \mathrm{mg} /$ day). Three months later he was referred to our clinic for ocular side effects of ethanbutol; his condition had improved with the treatment and he had no ocular symptoms.

Ocular examination on 28 July 1986 showed a best corrected visual acuity of $20 / 20$. The intraocular pressure was $18 \mathrm{mmHg}$ in both eyes. He had normal ocular movements and normal pupillary reactions. No abnormal findings were noted in the anterior segment, lens, or vitreous of either eye. Ophthalmoscopic examination of the right eye showed a small white lesion inferotemporal to the macula (Fig 1). In the left eye multiple disseminated dark-red haemorrhages with blurred margins were noted in the posterior pole (Fig 2). The retinal vessels coursed over the haemorrhages. These findings suggested that the haemorrhages were in the choroid. In addition

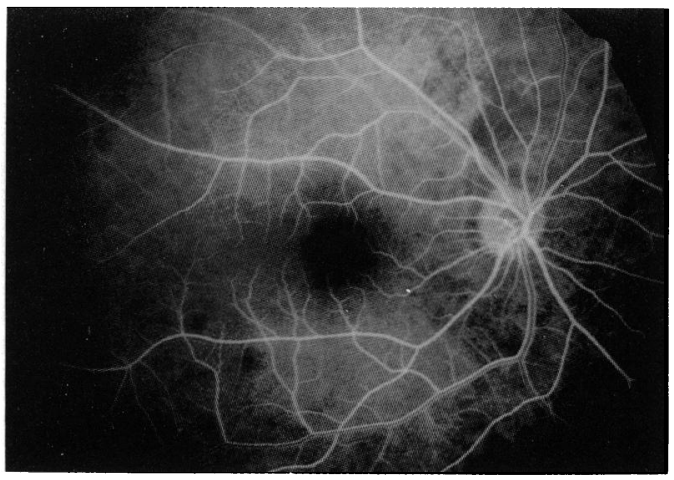

Figure 3: Right eye: fluorescein angiography shows hypofluorescent lesions, one of which corresponds to the white lesion seen ophthalmoscopically. 


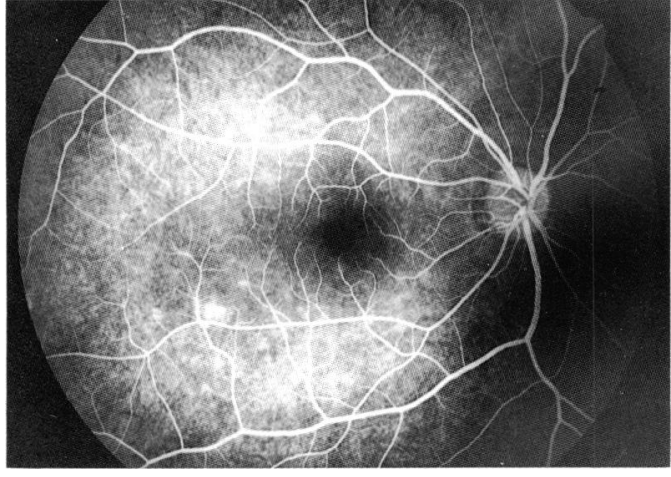

Figure 4: Right eye: the lesions hyperfluoresce in the late phase.

one retinal haemorrage was noted in the upper region of the macula. Fluorescein angiography of the right eye revealed focal areas of hypofluorescence in the early phase, one of which corresponded to the white lesion seen ophthalmoscopically inferotemporal to the macula (Fig 3). Later the lesions hyperfluoresced (Fig 4). In the left eye there were disseminated hypofluorescent lesions corresponding to the haemorrhages and focal areas of hyperfluorescence (Fig 5) that enlarged with time. A haemogram at that time showed the following values: WBC, $7.5 \times 10^{9} / 1$; $\mathrm{RBC}, 3.9 \times 10^{12} / \mathrm{l} ; \mathrm{Hb}, 10.2 \mathrm{~g} / \mathrm{dl}$; haematocrit, $31.0 \%$; and platelet count $359 \times 10^{9} / 1$. In one month the patient's general condition improved and the haemorrhages in the left eye began to disappear. Four months later no haemorrhages were seen ophthalmoscopically (Fig 6). However, fluorescein angiography revealed areas of hyperfluorescence with sharper margins than before (Fig 7). No ophthalmoscopic changes in the right fundus were observed during that time.

\section{Discussion}

Acute miliary tuberculosis results from bacteraemia in a person whose resistance is low, such as our patient who was taking a steroid. The ophthalmoscopic form of tuberculosis usually consists of nodules or tubercles that are greyish or white, have indistinct borders, and vary in size from one-sixth to two-thirds of a papillary diameter. ${ }^{1-3578}$ Angiographically the lesions are hypofluorescent initially, then show a hyperfluorescence that increases in size. ${ }^{2578}$ With

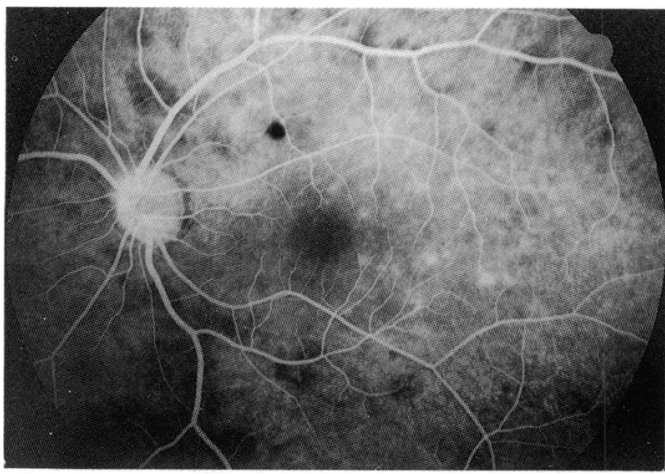

Figure 5: Left eye: fluorescein angiography shows hyperfluorescence that corresponds to the choroidal and retinal haemorrhages. Hyperfluorescent lesions also are seen temporal to the macula.

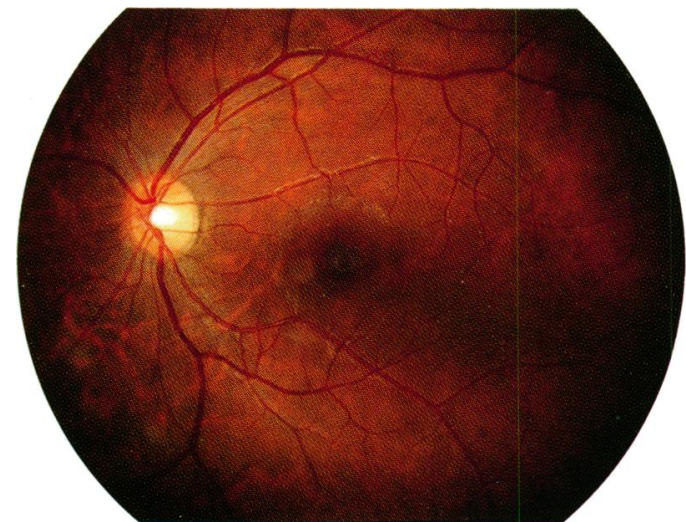

Figure 6: Left eye: after four months the haemorrhages have disappeared.

time the lesions resolve, leaving a scar with or without pigmentation. The scars also are hyperfluorescent and have sharp margins. The lesions observed in our patient's right eye corresponded to tubercles. The hyperfluorescent lesions seen in the left eye also seemed to correspond to small tubercles.

To our knowledge no reports have appeared on disseminated choroidal haemorrhages in miliary tuberculosis. Our patient had been on a regimen of isoniazid $(750 \mathrm{mg})$, rifampicin (450 $\mathrm{mg})$, and ethanbutol (750 $\mathrm{mg}$ ) daily. The therapy controlled the systemic miliary tuberculosis. There have been reports ${ }^{910}$ of retinal haemorrhages with use of ethanbutol, but the choroidal and retinal haemorrhages in our patient resolved as his systemic condition improved with therapy, which included ethanbutol. The results of laboratory data were within normal ranges. These haemorrhages thus appeared to be caused by miliary tuberculosis and were not a side effect of ethambutol therapy.

There has been a report ${ }^{2}$ of generalised miliary tuberculosis with retinal haemorrhages. We believe that miliary tuberculosis should be suspected in patients with disseminated choroidal haemorrhages, particularly in association with fever of unknown aetiology.

We thank Professor M Tamai from the Department of Ophthalmology, Tohoku University, for his helpful discussion and Ms M Gere for her review of this manuscript.

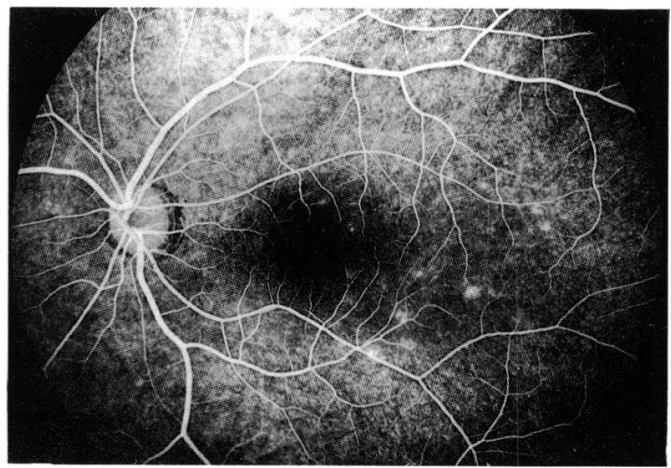

Figure 7: Left eye: fluorescein angiography discloses small hyperfluorescent lesions with sharp margins. 
1 Duke-Elder S. Tuberculosis. In: Duke-Elder S, ed. System of ophthalmology. London: Kimpton, 1967; 9: 246-81

2 Inoue $S$, Ubuka $M$. Fluorescein angiographic findings in a case of choroidal miliary tuberculosis. Folia Ophthalmol fpn 1972; 23: 256-9.

3 Yago K, Takahashi M. A case of miliary tuberculosis. Folia Ophthalmol fpn 1976; 27: 1172-6.

4 Cangemi FE, Friedman AH, Josephberg R, Tuberculoma of the choroid. Ophthalmology 1980; 87: 282-8.

5 Santoni G, Fiore C, Lupidi G, Galuppo L. Tuberculose miliaire chorö̈dienne: Etude angiofluorographique. Ophthalmologica 1982; 184: 6-12.
6 Jabbour NM, Bishara B, Trempe CL. A case of pulmonary tuberculosis presenting with a choroidal tuberculoma. Ophtuberculosis presenting with

7 Kiyosawa R, Ohnishi K, Ikeda T. A case of miliary tuberculosis. Folia Ophthalmol fpn 1985; 36: 652-6.

8 Funasaka K, Koshino M. A case of chorioretinal miliary tuberculosis. Fpn F Clin Ophthalmol 1986; 40: 30-4.

9 Carr RE, Henkind P. Ocular manifestations of ethambutol. Arch Ophthalmol 1962; 67: 566-71.

10 Yonekura Y, Mori T, Kondo N. Optic nerve damage caused by ethambutol. Folia Ophthalmol fpn 1969; 20: 545-9. 